\title{
Effect of a-tocopheryloxy acetic acid, a vitamin E derivative mitocan, on the experimental infection of mice with Plasmodium yoelii
}

\author{
Kasumi Kawamura ${ }^{\dagger}$, Aiko Kume $^{\dagger}$, Rika Umemiya-Shirafuji, Shunji Kasai and Hiroshi Suzuki $^{*}$ (1)
}

\begin{abstract}
Background: Malaria parasites are known to be vulnerable to oxidative stress. In this study, the effects of the administration of a-tocopheryloxy acetic acid (a-TEA), which is a vitamin E analogue mitocan, on Plasmodium yoelii infection in mice were examined.

Methods: Alpha-TEA was mixed with diet and fed to C57BL/6J mice before and/or after infection. For parasite infection, $4 \times 10^{4}$ red blood cells infected with P.yoelii (strain 17XL) were inoculated by intraperitoneal injection. In another series of experiment, the effect of the oral administration of a-TEA on P. yoelii 17XL infection in mice was examined. Finally, the combined effect of a-TEA and dihydroartemisinin or chloroquine on P. yoelii 17XL infection was examined.

Results: When $0.25 \%$ a-TEA was mixed with the diet for 7 days before infection and 14 days after infection (in total for 21 days), for 14 days after infection, and for 11 days from the third day after infection, all P. yoelii 17XL-infected mice survived during the observation period. However, all control mice died within 12 days after infection. These results indicated that a-TEA functions effectively even when administered post-infection. The oral administration of a-TEA for P. yoelii 17XL infection was also significant. Although the infected mice in the solvent control died within 10 days after infection, $90 \%$ of the mice infected with P. yoelii $17 \mathrm{XL}$ survived during the observation period when treated with $10 \mathrm{mg} / \mathrm{head} /$ day of a-TEA for 3 days from day 3 after infection. Although the combined effect of a-TEA and dihydroartemisinin (DHA) or chloroquine on P. yoelii 17XL infection was significant, no synergistic or additive effects were observed from the survival curve.

Conclusions: This study showed the beneficial effects of a-TEA on the experimental infection of mice with $P$. yoelii $17 X \mathrm{~L}$. The stimulatory action of a-TEA on mitochondria and the accompanying reactions, such as reactive oxygen species production, and induction of apoptosis might have some effect on malarial infection.
\end{abstract}

Keywords: a-tocopheryloxy acetic acid, Mice, Plasmodium yoelii, Reactive oxygen species

*Correspondence: hisuzuki@obihiro.ac.jp

†Kasumi Kawamura and Aiko Kume contributed equally to this work National Research Center for Protozoan Diseases, Obihiro University of Agriculture and Veterinary Medicine, Nishi 2-13, Inada-cho, Obihiro, Hokkaido 080-8555, Japan

\section{Background}

Malaria is a protozoan infection with fever, anaemia, and splenomegaly as the main symptoms. As one of the three major global infectious diseases, about half of the world's population is at risk of malaria. In 2019, there were 229 million cases and 409,000 deaths from malaria. In particular, children under the age of five are most susceptible

(c) The Author(s) 2021. This article is licensed under a Creative Commons Attribution 4.0 International License, which permits use, sharing, adaptation, distribution and reproduction in any medium or format, as long as you give appropriate credit to the original author(s) and the source, provide a link to the Creative Commons licence, and indicate if changes were made. The images or other third party material in this article are included in the article's Creative Commons licence, unless indicated otherwise in a credit line to the material. If material is not included in the article's Creative Commons licence and your intended use is not permitted by statutory regulation or exceeds the permitted use, you will need to obtain permission directly from the copyright holder. To view a copy of this licence, visit http://creativecommons.org/licenses/by/4.0/. The Creative Commons Public Domain Dedication waiver (http://creativecommons.org/publicdomain/zero/1.0/) applies to the data made available in this article, unless otherwise stated in a credit line to the data. 
to malaria, accounting for two-thirds of malaria deaths worldwide [1].

Protozoa, including this malaria parasite, are vulnerable to oxidative stress, and reactive oxygen species (ROS) intermediate the haemolysis of host erythrocytes, endothelial damage, and parasite death in malaria [2, 3]. Vitamin $\mathrm{E}$ is a fat-soluble antioxidant and its derivatives produce ROS and exhibits anticancer activity [4, $5]$. Alpha-tocopheryl succinate ( $\alpha$-TOS), a derivative of vitamin $E$, showed anticancer activity against HER2positive breast cancer in mice [6, 7]. For malaria infection, administration of $50-100 \mathrm{mM}$ of $\alpha$-TOS on days 1 , 3,5 , and 7 after infection with Plasmodium yoelii (strain $17 \mathrm{XL}$ ) or Plasmodium berghei (strain ANKA) resulted in a significant increase in host survival in mice [8]. However, since this chemical compound is decomposed by an esterase it has low stability and clinical application may be challenging. Therefore, in this study, the effects of $\alpha$-tocopheryloxy acetic acid ( $\alpha$-TEA), which is a more stable vitamin E derivative [9], and concomitant use with existing drugs on $P$. yoelii infection in mice were examined. Alpha-TEA is a vitamin E derivative derived and synthesized from $\alpha$-tocopherol that has an ether bond and is not decomposed by esterase, thus, it can be taken orally $[10,11]$.

\section{Methods}

C57BL/6 J mice were purchased from Japan CLEA (Tokyo, Japan) and bred in a specific pathogen-free facility. Experimental infection with $P$. yoelii was performed using male mice at a biosafety level 2 facility. The room temperature $\left(24 \pm 1{ }^{\circ} \mathrm{C}\right)$ and humidity $(50 \pm 10 \%)$ were regulated, and lighting was controlled (lights on from 7:00 to 19:00). Mice had free access to water and a commercial regular diet (CA-1; CLEA Japan, Tokyo, Japan). The animals used in this study were treated and cared for based on the Guiding Principles for the Care and Use of Research Animals established by Obihiro University of Agriculture and Veterinary Medicine. All animal experimental protocols were approved by the Institutional Animal Ethics Committee, Obihiro University of Agriculture and Veterinary Medicine (Approval number \#20-125).

Alpha-TEA distributed by Eisai (Eisai Co., Ltd., Tokyo, Japan) were mixed with diet $(0.083 \%$ and $0.25 \%(\mathrm{w} / \mathrm{w})$ of $\alpha$-TEA) and fed to C57BL/ 6 J male mice over 8 weeks of age (23-25 g body weight) for 7 days before infection and 14 days after infection (in total for 21 days), for 14 days after infection, and for 11 days from day 3 after infection. Hahn et al. examined the antitumor effect of dietary administration of $\alpha$-TEA in mice, and showed that $\alpha$-TEA had a significant dose-dependent antitumor effect at a dose of 0.05 to $0.3 \%$ [12]. With reference to this report, $0.083 \%$ (low dose) and $0.25 \% \alpha$-TEA diet (high dose) groups were provided in this study. In order to examine the effect of prophylactic administration of the drug, an experimental group was provided as pre- and post-infection administration. The preparation of the mixed-diet was outsourced to CLEA Japan. For preparation of parasites, mice were intraperitoneally administered with 200 $\mu \mathrm{L}$ of cryopreserved infected erythrocytes after thawing at $37^{\circ} \mathrm{C}$ in water bath. When parasitaemia of the mice exceeded to $10 \%, 40 \mu \mathrm{L}$ of blood was collected and mixed with $400 \mu \mathrm{L}$ of PBS, and of which $200 \mu \mathrm{L}$ was intraperitoneally administered to mice. Then, blood was collected when the parasitaemia exceeded to $10 \%$ and mixed with PBS to adjust the concentration of infected erythrocytes to $2 \times 10^{5} / \mathrm{mL}$ [8]. For parasite infection, $4 \times 10^{4} P$. yoelii 17XL-infected red blood cells (iRBCs) were inoculated by intraperitoneal injection in $\alpha$-TEA-treated mice and control mice fed a normal diet, and their parasitaemia and survival rates were monitored. The day of infection was defined as day 0 . From day 3 after infection, $2 \mu \mathrm{L}$ of peripheral blood was collected from the tip of the tail, smeared on a glass slide, stained with Giemsa (SigmaAldrich, Tokyo, Japan), and the proportion of infected erythrocytes in total erythrocytes (parasitaemia) was determined using a phase-contrast microscope (DIAPHOTO-TMD300, Nikon, Tokyo, Japan). Over 1,000 erythrocytes were counted in each mouse to assess parasitaemia.

In another series of experiment, the effect of the oral administration of $\alpha$-TEA on $P$. yoelii 17XL infection in mice was examined. Alpha-TEA was dissolved with 20\% DMSO (Dimethyl sulfoxide, Sigma-Aldrich, Tokyo, Japan) in PEG-300 (Polyethylene Glycol 300, Wako, Osaka, Japan). As a preliminary experiment, the pharmacokinetics of single and repeated oral administration of $\alpha$-TEA was observed, and no abnormalities were observed in the general condition, body weight transition, and liver function markers of the mice under any of the administration conditions. Male mice were infected with $4 \times 10^{4}$ P. yoelii $17 \mathrm{XL}$ iRBCs and orally administered $0,1,3$, and $10 \mathrm{mg} / \mathrm{head} /$ day of $\alpha$-TEA from days 3 to 5 after infection, and their parasitaemia and survival rate were monitored.

Finally, the combined effect of $\alpha$-TEA and dihydroartemisinin (DHA) or chloroquine on P. yoelii 17XL infection was examined. Male mice were infected with $4 \times 10^{4}$ P. yoelii 17XL iRBCs and orally administered $3 \mathrm{mg} /$ head/day of $\alpha$-TEA and intraperitoneally injected with $1 \mathrm{mg} / \mathrm{kg} /$ day of DHA (D3793, Tokyo Chemical Industry Co., Ltd., Tokyo, Japan) or $1 \mathrm{mg} / \mathrm{kg} /$ day of chloroquine (C6628, Sigma-Aldrich Japan, Tokyo, Japan) from days 3 to 5 after infection. When the combined effect of the two compounds was examined, in order to clarify the combined effect of the two compounds, the doses at which a 
survival rate of about $50 \%$ was observed when each drug was administered alone were used [13, 14].

As the control, a solvent control group (0 mg $\alpha$-TEA) in which the parasite and the solvent were administered and a control group in which only the parasite was administered were provided. Each infectious experiment was repeated at least three times and showed typical and representative results. Parasitaemia was analysed using the One-way ANOVA and Tukey test. Survival rate was analysed using the log-rank (Mantel-Cox) and GehanBreslow-Wilcoxon tests implemented in GraphPad Prism 5. For all analyses, a value of $\mathrm{p}<0.05$ was considered statistically significant.

\section{Results}

As shown in Fig. 1 , the effect of $\alpha$-TEA mixed with diet on $P$. yoelii $17 \mathrm{XL}$ infection was significant. When $0.25 \%$ $\alpha$-TEA was mixed with the diet for 7 days before infection and 14 days after infection (in total for 21 days), for 14 days after infection, and for 11 days from the third day after infection, all $P$. yoelii 17XL-infected mice survived during the observation period. However, all control mice died within 12 days after infection. Although the effect of lower concentrations of $\alpha$-TEA $(0.083 \%)$ was limited, the survival rate remained significantly higher than that of the control group $(\mathrm{P}<0.05)$. Regarding parasitaemia (Fig. 2), the control and $0.083 \%$ groups showed almost the same changes in proportions of parasitaemia after infection, and there was no significant difference between the two groups $(P>0.05)$. When $0.25 \% \alpha$-TEA was administered for 7 days before infection and 14 days after infection (in total for 21 days), proportions of parasitaemia were significantly higher than when $0.25 \% \alpha$-TEA was administered for 14 days after infection on days 8 , 10,12 , and 14 after infection $(\mathrm{P}<0.05)$, and for 11 days after infection on days $4,8,10,12$, and 14 after infection $(\mathrm{P}<0.05)$. Therefore, it was clarified that $\alpha$-TEA functions effectively even when administered post-infection. And the prophylactic effect of $\alpha$-TEA on parasitaemia may be limited.

As shown in Fig. 3, the oral administration of $\alpha$-TEA for $P$. yoelii 17XL infection was also significant. Although the infected mice in the solvent control $(0 \mathrm{mg} \alpha$-TEA) died within 10 days after infection, $90 \%$ of the mice infected with $P$. yoelii 17XL survived during the observation period when treated with $10 \mathrm{mg} / \mathrm{head} /$ day of $\alpha$-TEA for 3 days from day 3 after infection. The survival rates of the $10 \mathrm{mg} / \mathrm{head} /$ day group were significantly higher than those in the 1 and $3 \mathrm{mg} / \mathrm{head} /$ day groups $(\mathrm{P}<0.05)$. The survival rates of the 3 and $10 \mathrm{mg} / \mathrm{head} /$ day groups were significantly higher than that of the solvent control group $(\mathrm{P}<0.05)$. When the infected mice were treated with $\alpha$-TEA for 3 days from day 5 after infection, the survival rate decreased to about half that of the treatment from the third day. For parasitaemia (Fig. 4), although all experimental groups showed an increase in the

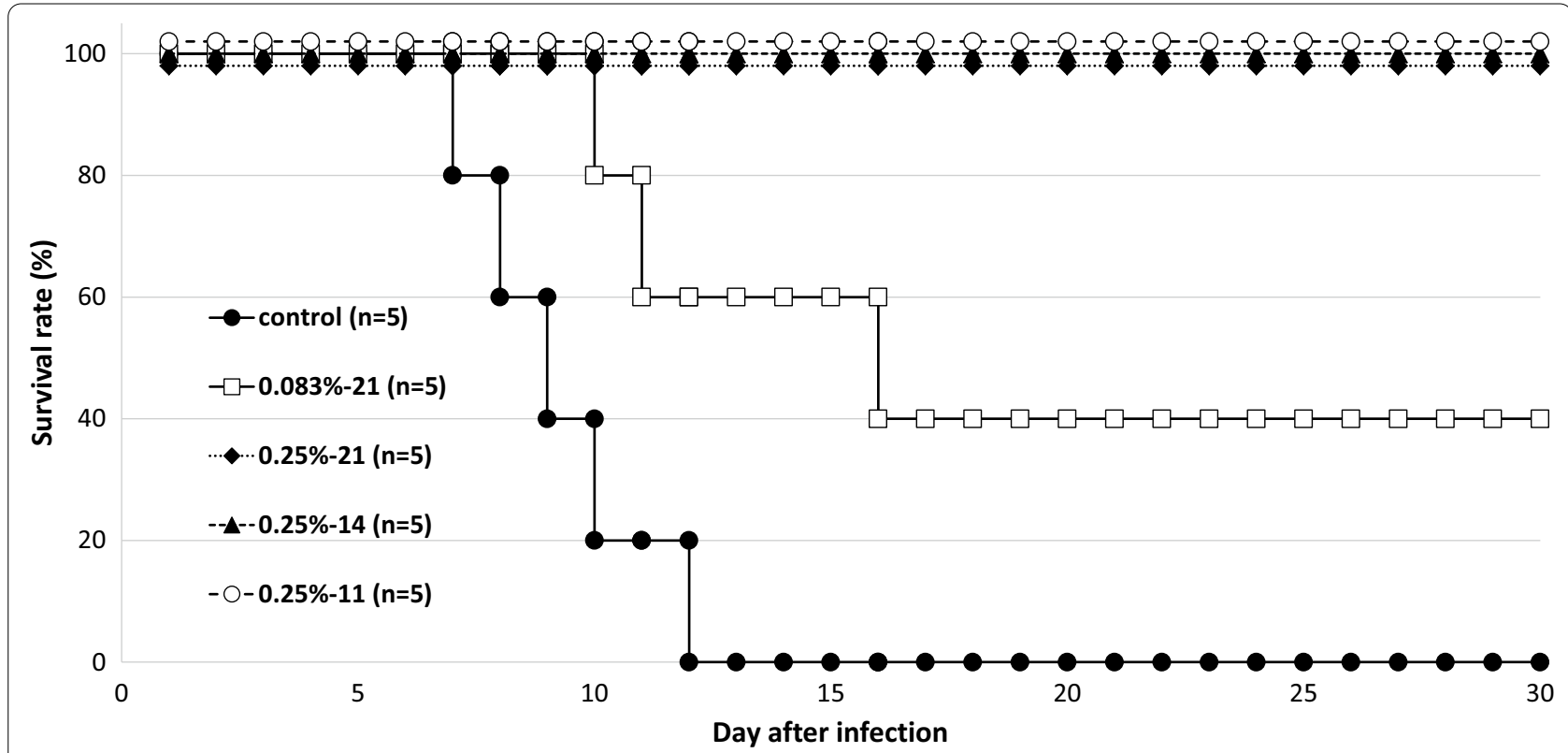

Fig. 1 Effect of a-TEA mixed with diet on survival after P. yoelii 17XL infection in mice. In total, 0.083\% and 0.25\% (w/w) a-TEA were mixed with diet and fed to C57BL/6J mice for seven days before $4 \times 10^{4} \mathrm{iRBCs}$ and 14 days after infection $(0.083 \%-21,0.25 \%-21)$, for 14 days after infection $(0.25 \%-14)$, and for 11 days from the third day after infection (0.25\%-11). Control vs. $0.083 \%-21 ; P<0.05$. Control vs. $0.25 \%-21,-14$, and $-11 ; P<0.05$. $0.083 \%-21$ vs. $0.25 \%-21,-14$, and $-11 ; P=0.05$ 

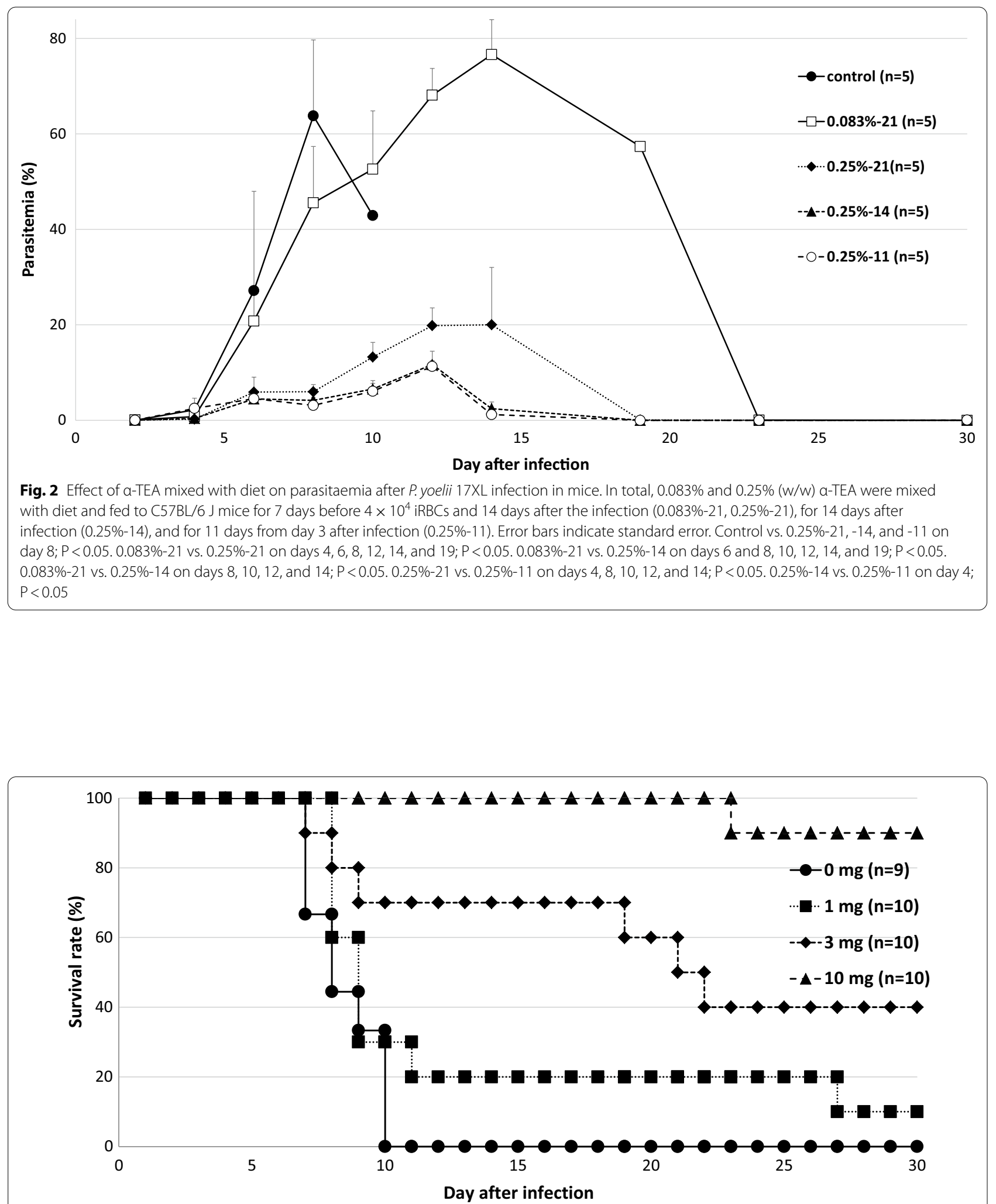

Fig. 3 Effect of oral administration of a-TEA on survival after P. yoelii 17XL infection in mice. C57BL/6 J mice infected with $4 \times 10^{4}$ iRBCs were orally administered $0,1,3$, and $10 \mathrm{mg} /$ head/day of a-TEA for 3 days from day 3 after infection. As the control, a solvent control group ( $0 \mathrm{mg}$ a-TEA) in which the parasite and the solvent were administered was provided. $10 \mathrm{mg} / \mathrm{head} /$ day vs. 0,1 , and $3 \mathrm{mg} / \mathrm{head} /$ day; $\mathrm{P}<0.05 .3 \mathrm{mg} / \mathrm{head} / \mathrm{day} \mathrm{vs}$. $0 \mathrm{mg} /$ head/day; $\mathrm{P}<0.05$ 


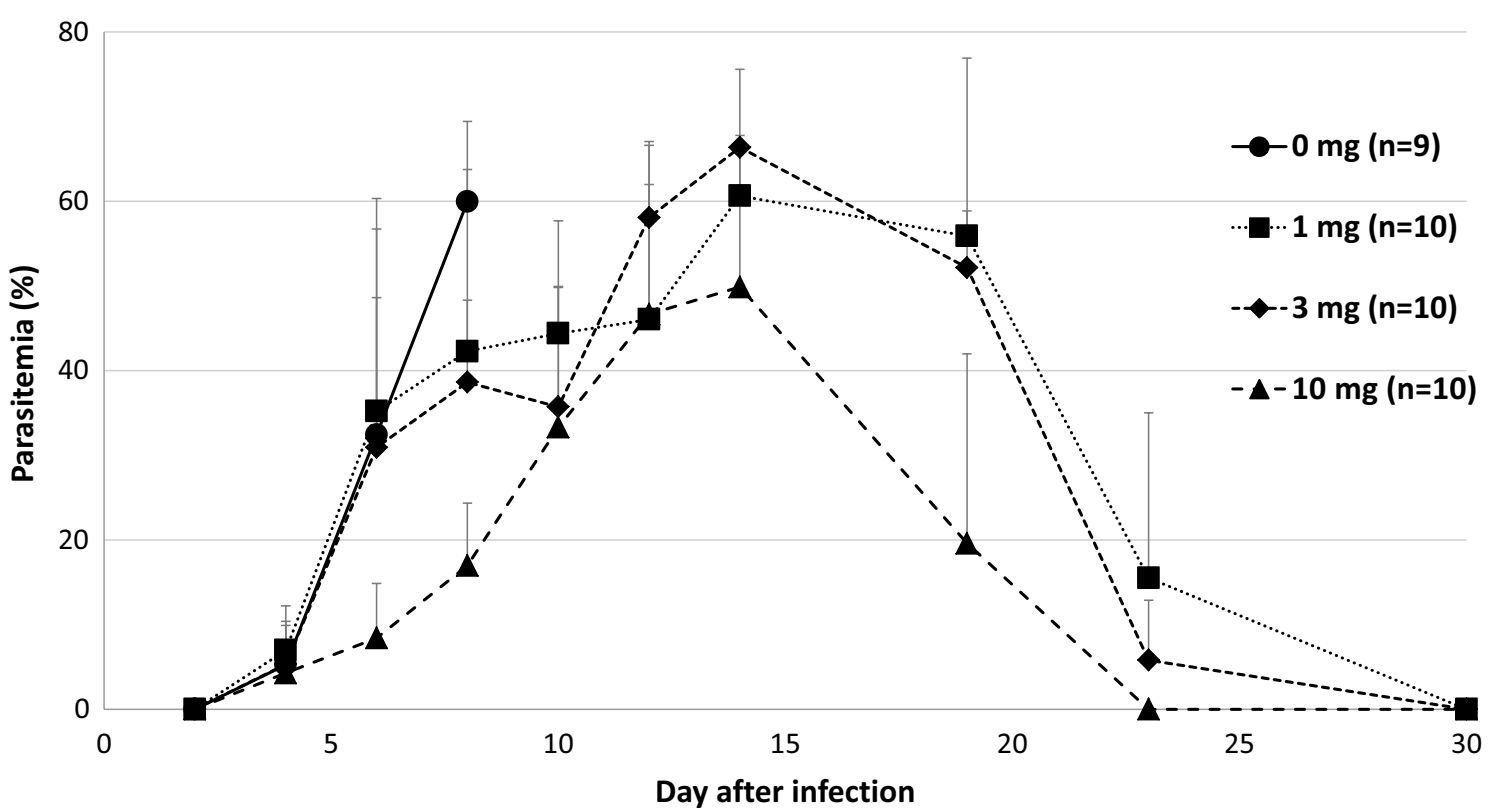

Fig. 4 Effect of the oral administration of a-TEA on parasitaemia after P. yoelii 17XL infection in mice. C57BL/6 J mice infected with $4 \times 10^{4}$ iRBCs were orally administered $0,1,3$, and $10 \mathrm{mg} /$ head/day of a-TEA for 3 days from day 3 after infection. As the control, a solvent control group (0 mg $\mathrm{a}$-TEA) in which the parasite and the solvent were administered was provided. Error bars indicate standard error. $0 \mathrm{mg} / \mathrm{head} / \mathrm{day} \mathrm{vs} .3 \mathrm{mg} / \mathrm{head} / \mathrm{day}$ on day $6 ; \mathrm{P}<0.05 .0 \mathrm{mg} / \mathrm{head} /$ day vs. $10 \mathrm{mg} / \mathrm{head} /$ day on days 6 and $8 ; \mathrm{P}<0.05 .1 \mathrm{mg} /$ head/day vs. $10 \mathrm{mg} / \mathrm{head} /$ day on days 6,8, and $19 ; \mathrm{P}<0.05$. $3 \mathrm{mg} / \mathrm{head} /$ day vs. $10 \mathrm{mg} / \mathrm{head} /$ day on days $6,8,14$, and $19 ; \mathrm{P}<0.05$

proportion of parasitaemia after infection, the proportions in the 3 and $10 \mathrm{mg} / \mathrm{head} /$ day groups on day 6 after infection were significantly lower than in the solvent control group $(\mathrm{P}<0.05)$. In addition, the proportion of parasitaemia in the $10 \mathrm{mg} / \mathrm{head} /$ day group was significantly lower than those in the 1 and $3 \mathrm{mg} /$ head/day groups on days 6,8 , and 19 after infection $(\mathrm{P}<0.05)$.

Figure 5 shows the combined effect of $\alpha$-TEA and DHA on survival after $P$. yoelii $17 \mathrm{XL}$ infection in mice. There was no significant difference in survival rate after infection between the solvent and untreated controls. All solvent control mice and non-treated control mice died by day 9 and 23 post-infection, respectively. When mice were administered both $\alpha$-TEA ( $3 \mathrm{mg} / \mathrm{head} /$ day) and DHA $(1 \mathrm{mg} / \mathrm{kg} /$ day) for 3 days from day 3 after infection, they showed higher survival compared with both the solvent and non-treated control groups $(\mathrm{P}<0.05)$, but not the $\alpha$-TEA $(\mathrm{P}=0.06)$ and DHA $(\mathrm{P}>0.05)$ groups. As shown in Fig. 6, parasitaemia remained similar in all experimental groups, but there was a significant difference between DHA and the combination group on day 4 $(\mathrm{P}<0.05)$.

As shown in Fig. 7, although the combined effect of $\alpha$-TEA and chloroquine on P. yoelii 17XL infection was significant, no synergistic or additive effects were observed from the survival curve. Namely, survival after the combined administration of $\alpha$-TEA ( $3 \mathrm{mg} /$ head/day) and chloroquine $(1 \mathrm{mg} / \mathrm{kg} /$ day) for 3 days from day 3 after infection was significantly higher than that in both controls and chloroquine $(\mathrm{P}<0.05)$, but not in the single administration of $\alpha$-TEA $(P>0.05)$. Chloroquine was used at sub-curative dose, so its effect was limited on the survival curve. In the transition of parasitaemia (Fig. 8), although the combination of $\alpha$-TEA and chloroquine tended to be similar to the $\alpha$-TEA and chloroquine alone groups. The proportions of parasitaemia in the $\alpha$-TEA and chloroquine combination groups were significantly lower than that in the control group on day 6 after infection $(\mathrm{P}<0.05)$.

\section{Discussion}

This study showed the beneficial effects of $\alpha$-TEA on the experimental infection of mice with $P$. yoelii 17XL. There have been some studies regarding the anti-tumour effects of $\alpha$-TEA [15-21], but the anti-pathogen or anti-protozoal effects have not yet been investigated. When $P$. yoelii $17 X L$-infected mice were treated with $\alpha$-TEA via being mixed into the diet or through oral administration, their viability was almost completely maintained (Figs. 1 and 3 ) and the parasites were eliminated from their blood (Figs. 2 and 4). However, the effect of pretreatment with $\alpha$-TEA on parasitaemia was limited. Specifically, there was no difference in survival rates whether administration commenced before or after infection, although there 


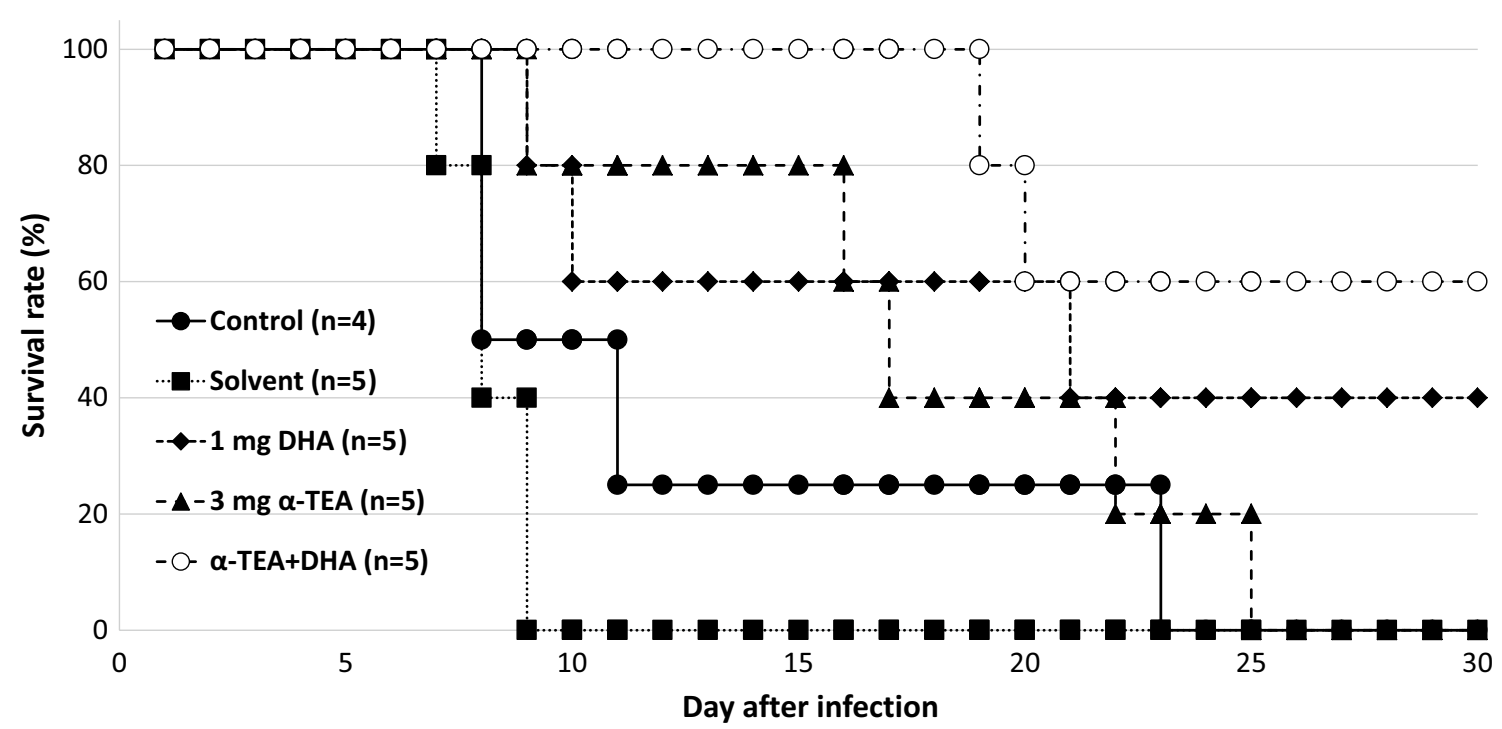

Fig. 5 The combined effect of a-TEA and DHA on survival after P. yoelii 17XL infection in mice. C57BL/6J mice infected with $4 \times 10^{4}$ iRBCs were administered $3 \mathrm{mg} / \mathrm{head} /$ day of a-TEA and $1 \mathrm{mg} / \mathrm{kg} /$ day DHA for 3 days from day 3 after infection. As the control, a solvent control group (0 mg $\mathrm{a}-\mathrm{TEA})$ in which the parasite and the solvent were administered and a control group in which only the parasite was administered were provided. Control and solvent vs. $a-T E A+D H A ; P<0.05$. Solvent vs. DHA and $a-T E A ; P<0.05$. $a-T E A$ vs. $a-T E A+D H A ; P=0.06$

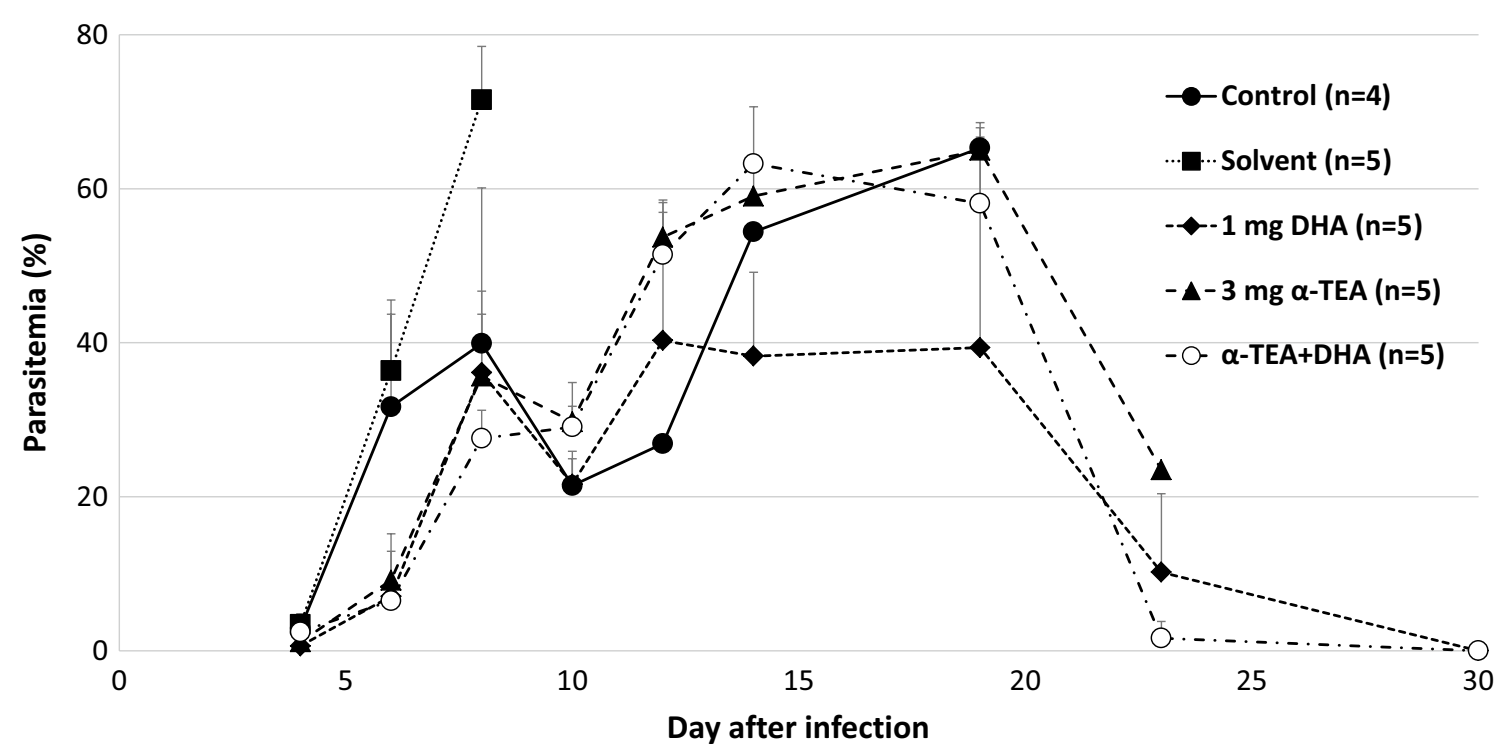

Fig. 6 The combined effect of a-TEA and DHA on parasitaemia after P. yoelii 17XL infection in mice. C57BL/6J mice infected with $4 \times 10^{4} \mathrm{iRBCs}$ were administered $3 \mathrm{mg} / \mathrm{head} /$ day of a-TEA and $1 \mathrm{mg} / \mathrm{kg} /$ day DHA for 3 days from day 3 after infection. As the control, a solvent control group (0 mg $a-T E A)$ in which the parasite and the solvent were administered and a control group in which only the parasite was administered were provided. Error bars indicate standard error. DHA vs. a-TEA + DHA on day 4; $P<0.05$

was a difference in the transition of parasitaemia. When comparing the groups that received $\alpha$-TEA either before or after infection, the latter significantly reduced parasitaemia on days $8,10,12,14$, and 19 after infection (Fig. 2, $\mathrm{P}<0.05)$. These data indicate that it may be possible to maintain parasitaemia lower by increasing the blood $\alpha$-TEA concentration just before the elevation of parasitaemia after malarial infection. Furthermore, $\alpha$-TEA may act directly on the protozoa rather than modifying the host environment. It has been reported that the 


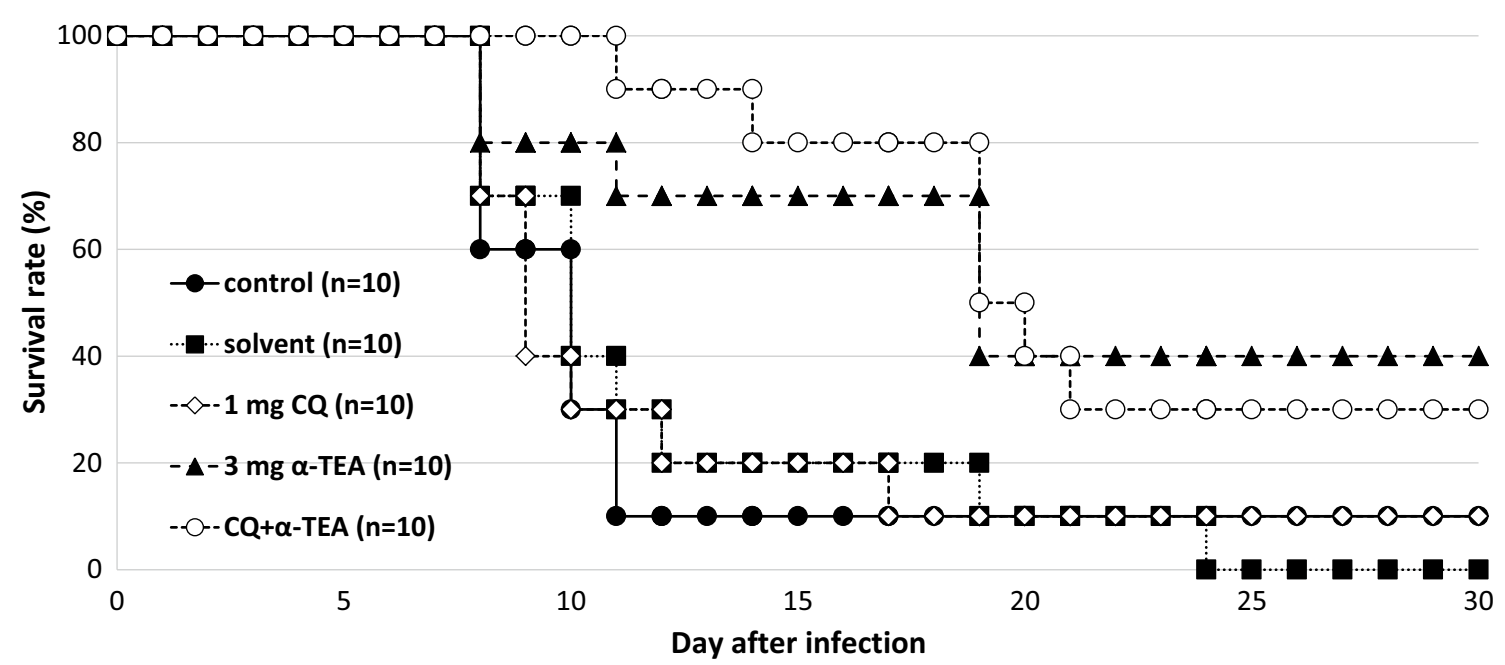

Fig. 7 The combined effect of a-TEA and chloroquine on survival after P. yoelii 17XL infection in mice. C57BL/6J mice infected with $4 \times 10^{4}$ iRBCs were administered $3 \mathrm{mg} / \mathrm{head} /$ day of a-TEA and $1 \mathrm{mg} / \mathrm{kg} /$ day chloroquine for 3 days from day 3 after infection. As the control, a solvent control group ( $0 \mathrm{mg}$ a-TEA) in which the parasite and the solvent were administered and a control group in which only the parasite was administered were provided. Control, solvent, and chloroquine vs. $a-T E A+$ chloroquine; $P<0.05$. Control vs. $a-T E A ; P=0.05$. Solvent vs. $a-T E A ; P<0.05$. $a-T E A$ vs. chloroquine; $\mathrm{P}<0.05$

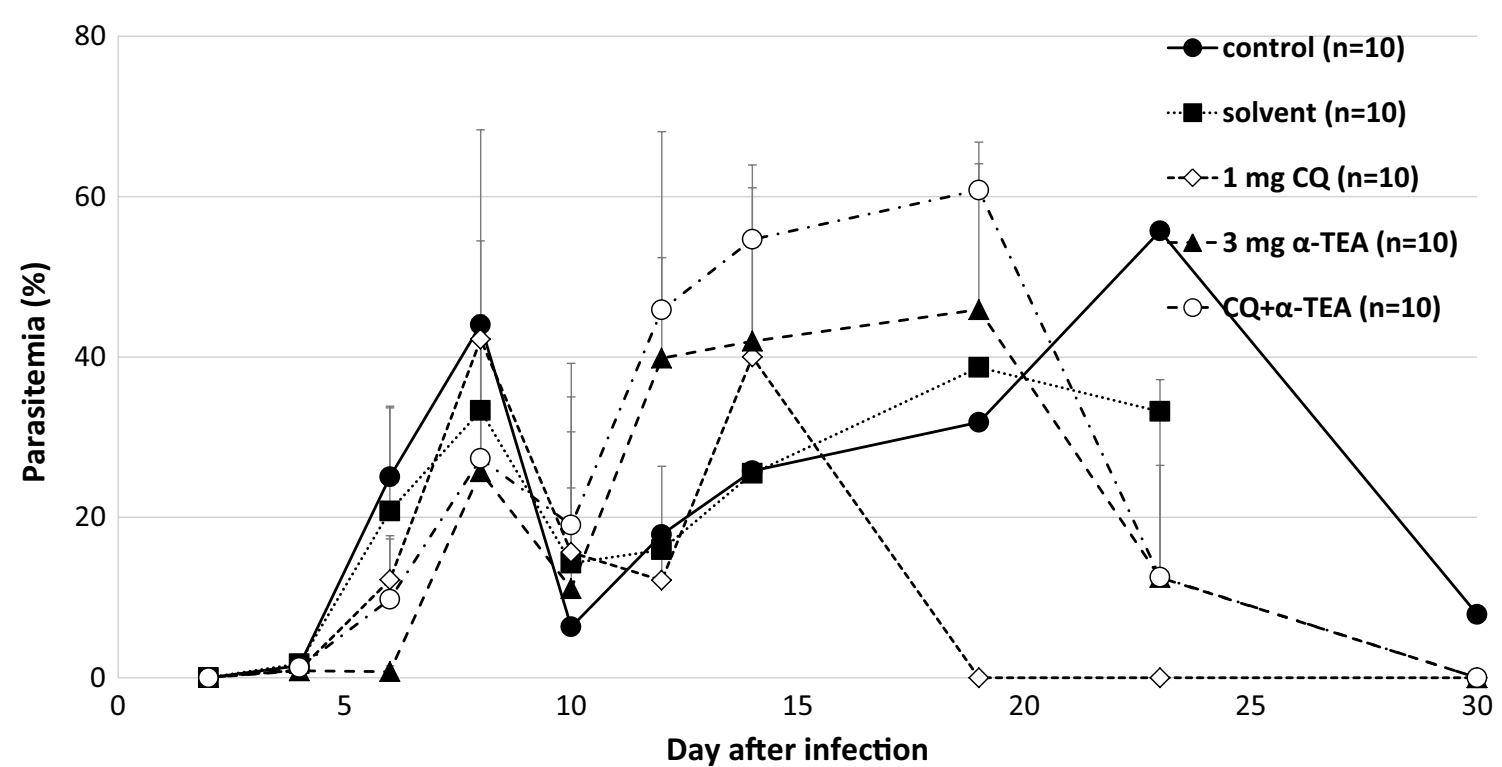

Fig. 8 The combined effect of a-TEA and chloroquine on parasitaemia after P. yoelii 17XL infection in mice. C57BL/6J mice infected with $4 \times 10^{4}$ iRBCs were administered $3 \mathrm{mg} / \mathrm{head} /$ day of a-TEA and $1 \mathrm{mg} / \mathrm{kg} /$ day chloroquine for 3 days from day 3 after infection. As the control, a solvent control group ( $0 \mathrm{mg}$ a-TEA) in which the parasite and the solvent were administered and a control group in which only the parasite was administered were provided. Error bars indicate standard error. Control vs. a-TEA + chloroquine on days 6, 10, and 19; P<0.05. Control vs. a-TEA on day $8 ; \mathrm{P}<0.05$

administration of $50-100 \mathrm{mM}$ of $\alpha$-TOS after P. yoelii $17 \mathrm{XL}$ infection significantly increases host survival in mice [8]. However, all $\alpha$-TOS-treated mice died within 20 days of infection, while $\alpha$-TEA administration rescued almost all infected mice in this study (Figs. 1 and 3). As
$\alpha$-TEA is not hydrolysed and has good stability [10, 11], it may be an effective anti-malarial drug candidate. In our preliminary pharmacokinetic experiment, in which $0.25 \%$ $\alpha$-TEA-mixed diet was fed to uninfected C57BL/6 J mice for 21 days, the average food intake of the mice was $3.6 \mathrm{~g} /$ 
head/day. The daily food intake was comparable to mice fed with a normal chew diet. From this value the average $\alpha$-TEA intake of mice is $9 \mathrm{mg} / \mathrm{head} /$ day. The elimination half-life $\left(\mathrm{T}_{1 / 2}\right)$ was $61.3 \mathrm{~h}$ after a single oral dose of $\alpha$-TEA (10 mg/head) in mice; the maximum concentration $\left(C_{\max }\right)$ was $25.7 \mu \mathrm{g} / \mathrm{mL}$ and the area under the blood concentration time curve (AUC) was $1780 \mu \mathrm{g} \cdot \mathrm{h} / \mathrm{mL}$. In addition, the mice orally administered with $\alpha$-TEA $(10 \mathrm{mg} /$ day) for 3 days had a plasma $\alpha$-TEA concentration of $10 \mu \mathrm{g} / \mathrm{mL}$ or higher for 6 days from the start of administration (Kasai et al., unpublished data).

When DHA was combined with $\alpha$-TEA for P. yoelii $17 \mathrm{XL}$ infection, no synergistic effect was observed. However, $\alpha$-TEA and DHA did not antagonize, and there may have been an additive effect (Fig. 5). The survival rate on day 30 was $0 \%$ in the $3 \mathrm{mg} \alpha$-TEA and $40 \%$ in the $1 \mathrm{mg}$ DHA group, whereas this was $60 \%$ in the DHA $(1 \mathrm{mg})$ with $\alpha$-TEA (3 mg) group. The survival rate by day 30 in the DHA with $\alpha$-TEA group was significantly higher than that in the control group $(\mathrm{P}<0.05)$. Although there was no difference between the DHA with $\alpha$-TEA group and DHA $(\mathrm{P}>0.05)$ and $\alpha$-TEA group $(\mathrm{P}=0.06)$, the survival rate tended to increase in the combined group. On the other hand, the combined use of $\alpha$-TEA and chloroquine in $P$. yoelii-infected mice did not have a clear combined effect on their survival rate (Fig. 7). In the combined group, parasitaemia increased sharply after the end of the administration period (Fig. 8), suggesting that the combination effect may be exerted more strongly by extending the administration period.

It remains unclear whether anti-malarial effects of $\alpha$-TEA were caused by impact on parasites directly, regulation of pathological mechanisms or enhancement of host defense mechanisms such as the immune system. However, parasites might certainly intake $\alpha$-TEA from plasma and erythrocyte membrane. In our preliminary experiment, the number of trypanosome was significantly lower following $\alpha$-TEA treatment than that after control treatment (no $\alpha$-TEA) in culture in vitro, suggesting that $\alpha$-TEA directly affected trypanosome. $\alpha$-TEA induced the production of ROS, such as hydroxyl radical and peroxynitrite, in protozoans. (Kawamura et al., unpublished observation). Oxidative stress may inhibit the development of parasite growth. Alpha-TEA stimulates mitochondria to produce ROS and induces the apoptosis of tumor cells [16, 20,22] as well as enhances the anti-tumour activity of trastuzumab against HER2/neu-expressing breast cancer $[17,18]$. As $\alpha$-TEA had a stronger inhibitory effect on breast cancer than $\alpha$-TOS, and is more stable in plasma [9], it is expected that the stimulatory action of $\alpha$-TEA on mitochondria [23] and the accompanying reactions, such as ROS production, induction of apoptosis, and stimulation of autophagy [19] might have some effect on malarial infection. Parasites exposed to
$\alpha$-TEA would readily accumulate ROS by interfering with the mitochondrial redox chain and activating the intrinsic apoptotic pathway. Endothelial cells deficient in mitochondrial DNA are resistant to $\alpha$-TEA, both in ROS accumulation and apoptosis induction, maintaining their angiogenic potential [24]. Furthermore, $\alpha$-TEA is a potent anti-tumor agent with a safe toxicity profile in mice [25] and dogs [26].

\section{Conclusion}

In this study, $\alpha$-TEA was effective against murine malaria, but no combination effect with DHA or chloroquine was observed. Since a sufficient anti-malarial effect can be obtained with $\alpha$-TEA alone, future studies could focus on the combined effect of $\alpha$-TEA with other existing drugs and consider a drug with a more combined effect. The prophylactic anti-malarial activity of premedication with $\alpha$-TEA may also be interesting. Furthermore, it is expected that this compound will be developed as an antiprotozoal drug by analysing the mechanism of action of $\alpha$-TEA and examining its effect on other protozoan infections in future.

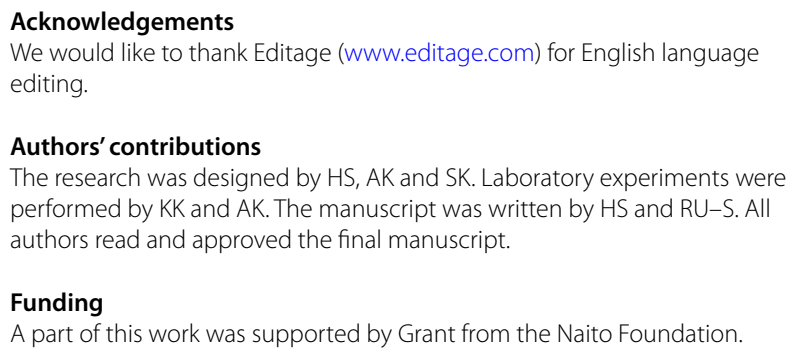

Availability of data and materials

The data that support the findings of this study are available from the corresponding author upon reasonable request.

\section{Declarations}

\section{Ethics approval}

The animals used in this study were treated and cared for based on the Guiding Principles for the Care and Use of Research Animals established by Obihiro University of Agriculture and Veterinary Medicine. All animal experimental protocols were approved by the Institutional Animal Ethics Committee, Obihiro University of Agriculture and Veterinary Medicine.

\section{Consent for publication}

Not applicable.

\section{Competing interests}

On behalf of all authors, the corresponding author states that there is no competing interest.

Received: 23 April 2021 Accepted: 14 June 2021

Published online: 24 June 2021

References

1. WHO. World Malaria Report. Geneva, World Health Organization, 2020. https://www.who.int/health-topics/malaria\#tab=tab_1. Accessed 12 Dec 2020. 
2. Friedman MJ. Oxidant damage mediates variant red cell resistance to malaria. Nature. 1979;280:245-7.

3. Clark IA, Hunt NH. Evidence for reactive oxygen intermediates causing hemolysis and parasite death in malaria. Infect Immun. 1983;39:1-6.

4. Kline K, Yu W, Sanders BG. Vitamin E and breast cancer. J Nutr. 2004;134(Supplement):3458S-S3462.

5. Neuzil J, Dong LF, Ramanathapuram L, Hahn T, Chladova M, Wang $X F$, et al. Vitamin $E$ analogues as a novel group of mitocans: anticancer agents that act by targeting mitochondria. Mol Aspects Med. 2007;28:607-45.

6. Wang XF, Witting PK, Salvatore BA, Neuzil J.Vitamin E analogs trigger apoptosis in HER2/erbB2-overexpressing breast cancer cells by signaling via the mitochondrial pathway. Biochem Biophys Res Commun. 2005;326:282-9.

7. Wang XF, Birringer M, Dong LF, Veprek P, Low P, Swettenham E, et al. A peptide conjugate of vitamin E succinate targets breast cancer cells with high erbB2 expression. Cancer Res. 2007;67:3337-44.

8. Kume A, Kasai S, Furuya H, Suzuki H. a-tocopheryl succinate-suppressed development of cerebral malaria in mice. Parasitol Res. 2018;117:3177-82.

9. Dong LF, Grant G, Massa H, Zobalova R, Akporiaye E, Neuzil J. a-Tocopheryloxyacetic acid is superior to a-tocopheryl succinate in suppressing HER2-high breast carcinomas due to its higher stability. Int J Cancer. 2012;131:1052-8.

10. Lawson KA, Anderson K, Menchaca M, Atkinson J, Sun L, Knight V, et al. Novel vitamin $E$ analogue decreases syngeneic mouse mammary tumor burden and reduces lung metastasis. Mol Cancer Ther. 2003;2:437-44.

11. Hahn T, Szabo L, Gold M, Ramanathapuram L, Hurley LH, Akporiaye ET. Dietary administration of the proapoptotic vitamin E analogue a-tocopheryloxyacetic acid inhibits metastatic murine breast cancer. Cancer Res. 2006;66:9374-8.

12. Hahn T, Fried K, Hurley HH, Akporiaye ET. Orally active a-tocopheryloxyacetic acid suppresses tumor growth and multiplicity of spontaneous murine breast cancer. Mol Cancer Ther. 2009:8:15701577.

13. Kume A, Anh MDT, Shichiri M, Ishida N, Suzuki H. Probucol dramatically enhances dihydroartemisinin effect in murine malaria. Malar J. 2016;15:472.

14. Herbas MS, Ueta YY, Ichikawa C, Chiba M, Ishibashi K, Shichiri M, et al. Alpha-tocopherol transfer protein disruption confers resistance to malarial infection in mice. Malar J. 2010;9:101.

15. Jia L, Yu W, Wang P, Sanders BG, Kline K. In vivo and in vitro studies of anticancer actions of alpha-TEA for human prostate cancer cells. Prostate. 2008:68:849-60.
16. Yu W, Tiwary R, Li J, Park SK, Jia L, Xiong A, et al. a-TEA induces apoptosis of human breast cancer cells via activation of TRAIL/DR5 death receptor pathway. Mol Carcinog. 2010;49:964-73.

17. Hahn T, Bradley-Dunlop DJ, Hurley LH, Von-Hoff D, Gately S, Mary DL, et al. The vitamin E analog, alpha-tocopheryloxyacetic acid enhances the anti-tumor activity of trastuzumab against HER2/neu-expressing breast cancer. BMC Cancer. 2011;11:471.

18. Hahn T, Jagadish B, Mash EA, Garrison K, Akporiaye ET. a-Tocopheryloxyacetic acid: a novel chemotherapeutic that stimulates the antitumor immune response. Breast Cancer Res. 2011;13:R4.

19. Li Y, Hahn T, Garrison K, Cui ZH, Thorburn A, Thorburn J, et al. The vitamin E analogue a-TEA stimulates tumor autophagy and enhances antigen cross-presentation. Cancer Res. 2012;72:3535-45.

20. Hahn T, Akporiaye ET. a-TEA as a stimulator of tumor autophagy and enhancer of antigen cross-presentation. Autophagy. 2013;9:429-31.

21. Yao J, Gao P, Xu Y, Li Z. a-TEA inhibits the growth and motility of human colon cancer cells via targeting RhoA/ROCK signaling. Mol Med Rep. 2016;14:2534-40.

22. Tiwary R, Yu W, Sanders BG, Kline K. a-TEA cooperates with MEK or mTOR inhibitors to induce apoptosis via targeting IRS/PI3K pathways. Br J Cancer. 2011;104:101-9.

23. Rodríguez-Enríquez S, Hernández-Esquivel L, Marín-Hernández A, Dong LF, Akporiaye ET, Neuzil J, et al. Molecular mechanism for the selective impairment of cancer mitochondrial function by a mitochondrially targeted vitamin E analogue. Biochim Biophys Acta. 2012;1817:1597-607.

24. Dong LF, Swettenham E, Eliasson J, Wang XF, Gold M, Medunic Y, et al. Vitamin $E$ analogues inhibit angiogenesis by selective induction of apoptosis in proliferating endothelial cells: the role of oxidative stress. Cancer Res. 2007;67:11906-13.

25. Hahn T, Akporiaye ET. Repeat dose study of the novel proapoptotic chemotherapeutic agent alpha-tocopheryloxy acetic acid in mice. Anti Cancer Drugs. 2012;23:455-64.

26. Guerrouahen BS, Hahn T, Alderman Z, Curti B, Urba W, Akporiaye ET. GMPgrade a-TEA lysine salt: a 28-day oral toxicity and toxicokinetic study with a 28-day recovery period in beagle dogs. BMC Cancer. 2016;16:199.

\section{Publisher's Note}

Springer Nature remains neutral with regard to jurisdictional claims in published maps and institutional affiliations.
Ready to submit your research? Choose BMC and benefit from:

- fast, convenient online submission

- thorough peer review by experienced researchers in your field

- rapid publication on acceptance

- support for research data, including large and complex data types

- gold Open Access which fosters wider collaboration and increased citations

- maximum visibility for your research: over $100 \mathrm{M}$ website views per year

At BMC, research is always in progress.

Learn more biomedcentral.com/submissions 